ISSN 2693-2504

\title{
Coffee Waste as Novel Bio-Adsorbent: Detoxification of Nickel from Contaminated Soil and Coriandrum Sativum
}

\section{SEPIDEH TAJIK ${ }^{1,2}$, PARISA ZIARATI ${ }^{1,2}$ and Luis CRUZ-RODRIGUEZ ${ }^{3,4^{*}}$}

\author{
${ }^{I}$ Nutrition \& Food Sciences Research Center, Tehran Medical \\ Sciences, Islamic Azad University Tehran-Iran (IAUMST) \\ ${ }^{2}$ Faculty of Pharmacy, Tehran Medical Sciences, Islamic Azad
University, Tehran-Iran
}

${ }^{3}$ CEO, ELIDAN america LLC, Fl, USA

${ }^{4}$ CEO, ELIDAN genome SAS, 1 avenue du Lycée, 77130 Montereau Fault Yonne; France

\author{
"Correspondence author \\ Prof. Dr. CRUZ-RODRIGUEZ Luis \\ ELIDAN America LLC \\ 6826 NW 77th CT \\ Miami, FL, \\ USA \\ E-mail : 1cr@elidan-genome.com \\ luis.cruzrguez@gmail.com
}

Submitted : 26 Aug 2020 ; Published : 13 Sept 2020

\begin{abstract}
According to the recent surveys, the air and soil pollution levels have risen from the toxic metals due to accumulation of these metals in soil and plants. These concerns have become one of the basic problems of agricultural products, which lead to food contamination. In recent years, the use of low-cost bio-adsorption has been considered which is mainly due to agricultural waste. It is worth mentioning that coffee consumption is over eleven billion tons per year around the world. Coffee bean waste (canephorat, Arabica) is solid and insoluble in water, which is why it is racked up and compiled in nature. Packed potting soil purchased from Tehran market. Meanwhile in 45 vases the Coffee waste (from $0 \%$ to 5\%) dry weight percentage were mixed by soil, due to observing the effect of Coffee waste as adsorbent and in defined times: 1, 10, 20, 30, 40 days in the study. ICP-MS. Ion concentration was addressed in three replicates determined the Nickel (Ni) contents in aerial parts of vegetable in treated and untreated samples. The soil, leaves of vegetable was digested by wet method according the standard protocol (AOAC). Mean values were calculated using Analysis of Variance, (ANOVA) and adsorption capacity varied by considering the effects of assorted parameters like contact time, initial concentrations, and adsorbent dose. It was acknowledged by the results that coffee bean waste (CBW) has more potential to adsorb Ni during the first days of the study $(p<0.001)$ and adsorption capacity was diversified by considering the effects of various parameters like contact time, initial concentrations, $\mathrm{pH}$, and absorbent dose. Coffee bean waste could acquire high level of Nickel in a short time and the uptake rate by edible vegetable plant is significantly afflicted by their concentrations in the contaminated soil $(p<0.05)$. A contact time of 30 days by $\% 3$ corianders was resulted to be optimum.
\end{abstract}

Keywords: Detoxification, Coffee bin waste, Toxic metals, soil, Nickel, Food Safety

\section{Introduction}

Some heavy metals are needed for the human body to metabolize, but at higher concentrations of these metals, poisoning occurs. Heavy metals are naturally dangerous and toxic [1-5]. Nickel compounds are specifically used as catalysts and pigments. In nickel-production or nickel-using industries, about $0.2 \%$ of the work force may be exposed to considerable and hazardous amounts of airborne nickel. In addition, nickel release, e.g. into cutting oils, and skin contact with nickelcontaining or nickel-plated tools and other items may add to a major occupational nickel hazard [6-15]. Vegetables usually contain more nickel than do other food items; high levels have been detected in legumes, spinach, lettuce and nuts. Several studies reveal a highly variable dietary intake of nickel; however, most averages are about 200-300 micrograms/day. In addition, skin contacts to a multitude of metal objects are significantly referred to a large number of individuals suffering from contact dermatitis and nickel allergy. Once you have been exposed to this ultra-hazardous chemical, you will know it by your body's extreme reaction. Immediate symptoms that your body shows a negative reaction to nickel exposure include irritated eyes, itchy skin, and shortness of breath, cough, and release of possible fluid in lungs. Unfortunately, long-term exposure to nickel could cause a plethora of more severe and ultimately fatal symptoms [16-18]. 
The use of bio-adsorbents to eliminate toxic heavy metals is a relatively inexpensive method with high potential. Adsorption is presented as an effective and low cost method, this process is powerful enough to bring contaminated water and soil with toxic metals to the standard level [19-20]. Coffee waste is one of the few products produced by coffee shops in the world; a large amount of this waste is dumped into the environment and causes pollution [21-22]. Coffee waste has the ability to remove $\mathrm{Cu}$ (II) and $\mathrm{Cr}$ (IV) from contaminated water. 20\% up to $26 \%$ of coffee waste consist of lignin, which has the ability to adsorb heavy metals [23-24]. On the other hand, conditions that increase the risk of many diseases such as cancer and even coronavirus: age, high blood pressure, obesity and diabetes, all of which are associated with the accumulation of heavy metals [23]. Heavy metal levels are higher in the elderly than in the young, heavy metals increase the risk of high blood pressure and are directly linked to obesity and diabetes [4]. Researches shows that coriandrum may protect the body in general and specially protecting the liver against heavy and toxic metals and may have a beneficial effect on a variety of skin infections as well as non-insulin dependent diabetes and dyspepsia. Also, this plant has anti-anxiety, sedative and pain relieving effects [25-29].

Possible routes and sources of contamination are high for entering food. Sources and routes of contamination are different based on type of products and geographical regions because each farm has a specific combination of environmental risk factors such as topography, land-use interactions, and the combination of these environmental risk factors on the frequency and transmission of food pathogens, which affect the risk of product contamination [20,30]. Chemical contaminants in fruits and raw vegetables may naturally be added during the production of crops, post harvesting and during the other process. Some of these chemical hazards and parameters associated with chemical contaminations in fruits and vegetables include mycotoxins, pesticides, illegal additives and colors, heavy metals, stable organic pollutants and other compounds [31-37]. Principally, spent coffee waste contains large amounts of organic compounds, i.e. fatty acids, lignin, cellulose, hemicellulose, and other polysaccharides, therefore, due to the presence of certain functional groups on the cell wall of the biomass in current study we study of it as bio-adsorbent. The main goal is finding suitable green method for removal of some heavy metals such Nickel from pharmaceutical effluent laboratories which was used as irrigated water and added to soil as a low-cost waste in a batch system by considering the effects of various parameters like initial concentration, $\mathrm{pH}$, contact time, agitation speed and bio-adsorbent dose.

\section{Materials and Method}

\section{Waste Water Effluent}

Effluents from 3 educational and research laboratories in pharmaceutical sciences Faculty, Tehran Medical Sciences, Islamic Azad University in Tehran, including, Nutrition and Food Sciences research center (Effluent 1-4), Toxicology (Effluent 5), Analytical and Inorganic chemistry (Effluent
6-10) were used in this study. Effluent 1, 2, 3 and Effluent 4 were from the same laboratory but were collected on separate occasions with a 2 week time interval. Although these effluents come from the same WWTP, they were treated as 4 different effluents due to the variability of their characteristics. This difference is attributed to the significant experiments which occurred following the first sampling event. After collection, the effluent was immediately transported to the research laboratory for analysis. Physico-chemical parameters such as $\mathrm{pH}$, Electrical Conductivity, Total Solids, Total Dissolved Solids, Total hardness, Chloride, Sulphate, Dissolved oxygen, Nickel concentrations were analyzed as per the standard methods [38-41].

\section{Estimation of Heavy Metals in Effluents}

The existence of heavy metal Nickel, in the soil and leaves samples as analyzed before and after treatment in specified times by ICP-MS after digestion of plant and soil samples by AOAC method. The plant samples were washed in deionized water dried up $\left(24 \mathrm{hrs}\right.$. at $\left.80^{\circ} \mathrm{C}\right)$ immediately to stabilize the tissue and stop enzymatic reactions. After drying, samples were supposed to pass a $1.0 \mathrm{~mm}$ screen using the appropriate Wiley Mill. After grinding, the sample were thoroughly mixed and a 5 to $8 \mathrm{~g}$ aliquot withdrawn regarding analyses and storage. Weighed 0.5 to $1.0 \mathrm{~g}$ of dried aerial parts of plants, then heated at $60{ }^{\circ} \mathrm{C}$ which where be grounded ( 0.5 to 1.0 $\mathrm{mm}$ ) and thoroughly homogenized, stabilized and placed in a tall-form beaker or digestion tube. Added $5.0 \mathrm{ml}$ concentrated HNO3 (65\%, Merck) and cover beaker with watch glass or place a funnel in the mouth of digestion tube and allow to stand overnight or until frothing subsides. Placing covered beaker on hot plate or digestion tube into block digester and heating it at $125^{\circ} \mathrm{C}$ for 1 hour. Then the digestion tube was removed and it was let out to cool. Added 1 to $2 \mathrm{ml} \mathrm{H}_{2} \mathrm{O}_{2} 30 \%$ (Merck) and digest at the same temperature. Repeated heating digestion process until the solution turned clear and transparent. In soil samples added additional $\mathrm{HNO} 3$ as needed to maintain a wet digest. Added dilute HNO3 (10\%), and deionized water to dissolve digest residue and bring sample to final volume.

All recoveries of the metal observed exceeded 95\%. Ni ion concentrations were determined in three replications by means of Varian Vista ICP-MS device. The intra-day (for samples collected during the same day) and inter-day (for samples collected during different days) precision and accuracy of the method were determined under the optimal working conditions by triplicate measurements of known $\mathrm{Ni}$ concentrations. The first standard stock solutions showed a $100.0 \mathrm{mgl} / \mathrm{Lit}$ concentration of Nickel (II) Nitrate and aqueous standard solutions were prepared from it by means of appropriate dilution with $10 \%$ nitric acid [43-46].

At the beginning of study, soil profile characteristics were observed and recorded by a packet penetrometer $(\mathrm{Cl}-700 \mathrm{~A}$, soil Test Inc., USA). Soil samples were mixed, homogenized and separated into three parts, $1 / 3$ of each sample was airdried and pass through a $2 \mathrm{~mm}$ sieve in order to determine $\mathrm{p}$ and $\mathrm{k}$ content, $\mathrm{pH}$ and electrical conductivity and particle- 
size distribution. The other $2 / 3$ was passed through a $2 \mathrm{~mm}$ sieve without drying and $1 / 3$ of it used to determine Nickel concentration by ICP-OES after digestion. The detection system used for the determination of heavy metal ions: Nickel, was NexION 300X ICP-MS (Perkin-Elmer, USA) The instrumental operating conditions for the determination of the elements.

\section{Bio-adsorbent}

Coffee waste is collected from remarkable local coffee shops in Tehran in June of 2019 , and dried up in an oven at $50^{\circ} \mathrm{C}$ for 48 hours. The studied Coffee waste samples during the Bioadsorption investigation for removing heavy metal: Nickel, were at natural state with no chemical or thermal treatment.

\section{Vegetable Sampling Method}

Packed Potting Soil purchased from recognized centers from Tehran market and 45 same vases in the same situation such as light, water, soil, temperature and other conditions were prepared. The seeds of Coriandrum sativum (coriander) were being planted directly on the treated and untreated soil samples in vases. Meanwhile in 40 vases the Coffee waste by $0.3 \%$, $0.5 \%, 1 \%, 2 \%, 3 \%, 5 \%$ dry weight percentage and were mixed by soil, due to observing the effect of Coffee waste as adsorbent and in specified times of 1, 10, 20, 30 and 40 days. Meanwhile 5 vases of seeds of Coriandrum sativum (coriander) were planted in the same situation as untreated samples for comparing the potential of Coffee waste adsorption in current study. All Coriander samples were watered each day by Deionized water. Nickel contents in the leaves of edible vegetable in treated and 5 vases as well as untreated soils were investigated. The leaves of edible vegetable samples which have been grown in these soil samples were studied. The soil and leaves of vegetable were digested by wet method according the standard protocol [40-43].

In every 10 days, Aerial parts of Coriander in companion to Coffee waste were separated in 40 days, washed by deionized water and digested by wet method according the standard protocol for determining Nickel contents. Bioaccumulation factors (BAF-s) were calculated for heavy metal content of plant parts $(\mathrm{mg} / \mathrm{kg}) /$ heavy metal content of soil $(\mathrm{mg} / \mathrm{kg})$, for the metal. The studied samples were observed by the same light situation and some circumstances in order to be compared with each other in order to determine the Coffee waste ability in adsorbing Nickel from soil and its potential to avoid transferring heavy metals to coriander and keep the edible vegetable safe. All physical and chemical properties and concentrations of heavy metal in soils, before and after adding Coffee waste in the growth period of cultivated Coriander were analyzed in every 10 days in a specified time of day.

\section{Total dissolved solids (TID)}

The total solid concentration in waste effluent represents the colloidal form and dissolved species. The probable reason for the fluctuation of value of total solid and subsequent the value of dissolved solids due to content collision of these colloidal particles. The rate of collision of aggregated process is also influenced by PH of these effluents [18, 20, 47].

\section{Chemical oxygen demand (COD)}

The chemical oxygen demand test (COD) determines, the oxygen required for chemical oxidation of organic matter with the help of strong chemical oxidant. The COD is a test which is used to measure pollution of domestic and industrial waste. The waste is measure in terms of equality of oxygen required for oxidation of organic matter to produce $\mathrm{CO} 2$ and water. It is a fact that all organic compounds with a few exceptions can be oxidizing agents under the acidic condition. COD test is useful in pinpointing toxic condition and presence of biological resistant substances. For COD determination samples were preserved using $\mathrm{H} 2 \mathrm{SO} 4$ and processed for $\mathrm{COD}$ determination after the entire sampling operation was complete [49-50].

\section{Biochemical oxygen demand (BOD)}

For BOD, 5 samples were immediately processed after Collection for the determination of initial oxygen and incubated at $20^{\circ} \mathrm{C}$ for 5 days for the determination of BOD5 [49-50].

\section{Statistical Analysis}

All measurements were carried out in triplicate. Data were expressed as the mean $\pm \mathrm{SE}$ (standard error). Data were analyzed using one-way analysis of variance (ANOVA) and SPSS Software v.12 (SPSS INC., Chicago, IL, USA). Duncan's multiple range tests was used to assess differences in Nickel contents in leaves, different dose of bio-adsorbent, different time and $\mathrm{pH}$ of the soil samples. The values reported here are means of five values. Each sample data was the mean of 5 subsamples. A $p$ value of 0.05 or less was considered as statistically significant.

\section{Results}

Chemical composition of the wastewater effluent of studied research laboratories profile in pharmacy faculty before treatment by Coffee waste been is shown in the table 1. Data is the mean of the effluent profiles.

\begin{tabular}{|l|l|}
\hline Parameters & The mean of Concentration \\
\hline $\mathrm{pH}$ & 4.18 \\
\hline $\begin{array}{l}\text { BOD5: Biochemical oxygen } \\
\text { demand }(\mathrm{mg} / \mathrm{L})\end{array}$ & 3022 \\
\hline $\begin{array}{l}\text { COD }(\mathrm{mg} / \mathrm{L}): \text { chemical } \\
\text { oxygen demand }\end{array}$ & 6700 \\
\hline $\begin{array}{l}\text { TSS }(\mathrm{mg} / \mathrm{L}) \text { : total suspended } \\
\text { solids }\end{array}$ & 54 \\
\hline $\begin{array}{l}\text { Total alkalinity as } \\
\text { CaCO3 }(\mathrm{mg} / \mathrm{L})\end{array}$ & 98 \\
\hline Lead $(\mathrm{mg} / \mathrm{L})$ & 1.65 \\
\hline Nickel $(\mathrm{mg} / \mathrm{L})$ & 540 \\
\hline Cadmium $(\mathrm{mg} / \mathrm{L})$ & 10.3 \\
\hline Mercury $(\mathrm{mg} / \mathrm{L})$ & 0.09 \\
\hline Zinc $(\mathrm{mg} / \mathrm{L})$ & 10.1 \\
\hline
\end{tabular}




\begin{tabular}{|l|l|}
\hline Cobalt $(\mathrm{mg} / \mathrm{L})$ & 1.15 \\
\hline Chromium $(\mathrm{mg} / \mathrm{L})$ & 1.01 \\
\hline Chloride $(\mathrm{mg} / \mathrm{L})$ & 1.31 \\
\hline Sulfide $(\mathrm{mg} / \mathrm{L})$ & 0.17 \\
\hline Nitrate $(\mathrm{mg} / \mathrm{L})$ & 6583 \\
\hline
\end{tabular}

waste had a pH of 5.2 (including acidic waste stream), whereas the $\mathrm{pH}$ of the waste of Educational and research laboratories on the whole was 4.18 as is shown in table 1 . Some heavy metal contents such as Cadmium in the wastewater were found to be much higher than the limits according to IS-3306 (1974). Most of the solids present were in a dissolved form, with practically no suspended solids.

Table 1: Characteristics of Wastewater from Nutrition and Food Sciences Research Center laboratories in Pharmacy Faculty; before treatment

As compared to BOD, COD was very high which is normal for effluent of such Food Toxicology and pharmaceutical laboratories. The mean content of BOD from 10 sub-samples was 3022 and the mean values of COD were $6700 \mathrm{mg} / \mathrm{L}$ for the sub-samples of studied effluent.

Wastes from Nutrition and Food Sciences research center' laboratory due to food toxicological projects and wet/acid digestion methods had acidic state contributed $50 \%$ of the total waste flow at $3600 \mathrm{~mm} 3 /$ day and had a $\mathrm{pH}$ of 1.4. The combined Analytical and Inorganic chemistry laboratories

This investigation was carried out to determine the accumulation of heavy metal: Nickel in Coffee bean waste (CBW) in contaminated soils by heavy metals result in research center, chemical and toxicology laboratories' pharmaceutical effluent and wastewater irrigated soil in the vicinity of sewage treatment plant (STP), Pharmacy Faculty, Tehran.

The samples were analyzed by wet digestion method and standardized international protocols were followed for the preparation of material and analysis of Nickel contents and analyzed by Inductively Coupled Plasma (ICP-OES) in Research Laboratory of Nutrition and Food Sciences Research Center, in Pharmaceutical faculty, Tehran Medical Sciences.

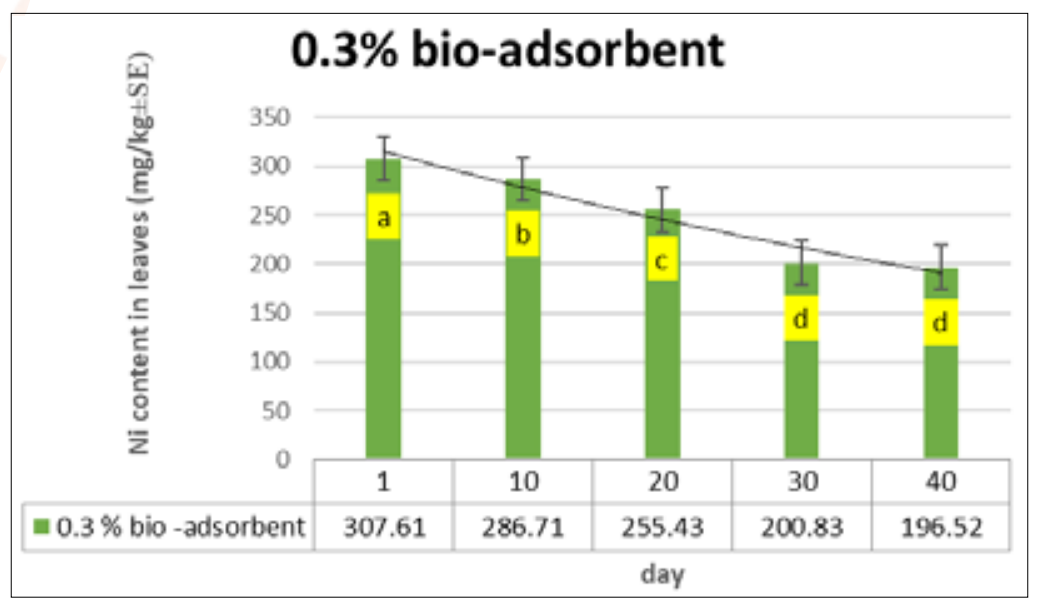

Figure 1: Effect of contact time on the removal of Nickel from leaves of vegetable (initial Ni concentration= $336.76 \mathrm{mg} / \mathrm{kg}$, bioadsorbent dose $=0.3 \%$ Coffee waste, temperature $=25 \pm 2{ }^{\circ} \mathrm{C}$.

Results from figure 1 revealed that Coffee waste has significant potential to adsorb Nickel $(p<0.05)$ during 30 days of study and after 30 days in presence of $0.3 \%$ of coffee waste, reduction of Nickel was not significant that approved that adsorption capacity varied by considering the effects of various parameters like contact time, initial concentrations, and absorbent dose.

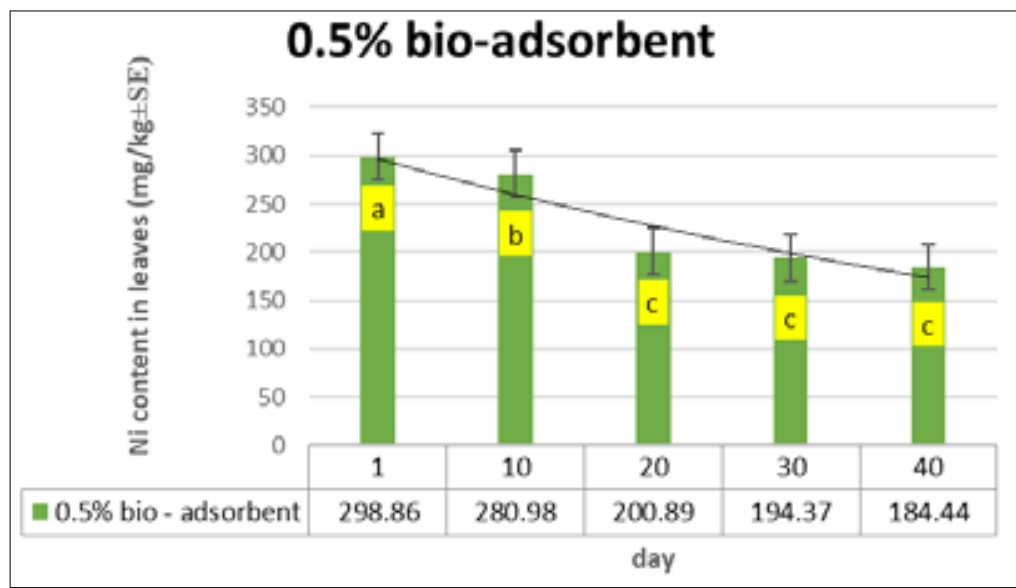

Figure 2 : Effect of contact time on the removal of Nickel from leaves of vegetable (initial Ni concentration=336.76 mg $/ \mathrm{kg}$, bioadsorbent dose $=0.5 \%$ Coffee waste, temperature $=25 \pm 2{ }^{\circ} \mathrm{C}$. 
Results in presence of $0.5 \%$ bio-adsorbent in figure 2 showed that in first days of study the potential of removal Nickel from vegetable leaves was so significant $(p<0.003)$ till 20 days but after this time although the Nickel content of can decreased but this trend was not significant. The adsorbent percentage by increasing the bio-mass content from $0.3 \%$ up to $0.5 \%$ proved that by boosting the bio-mass content the adsorbing would be affected significantly $(p<0.002)$.

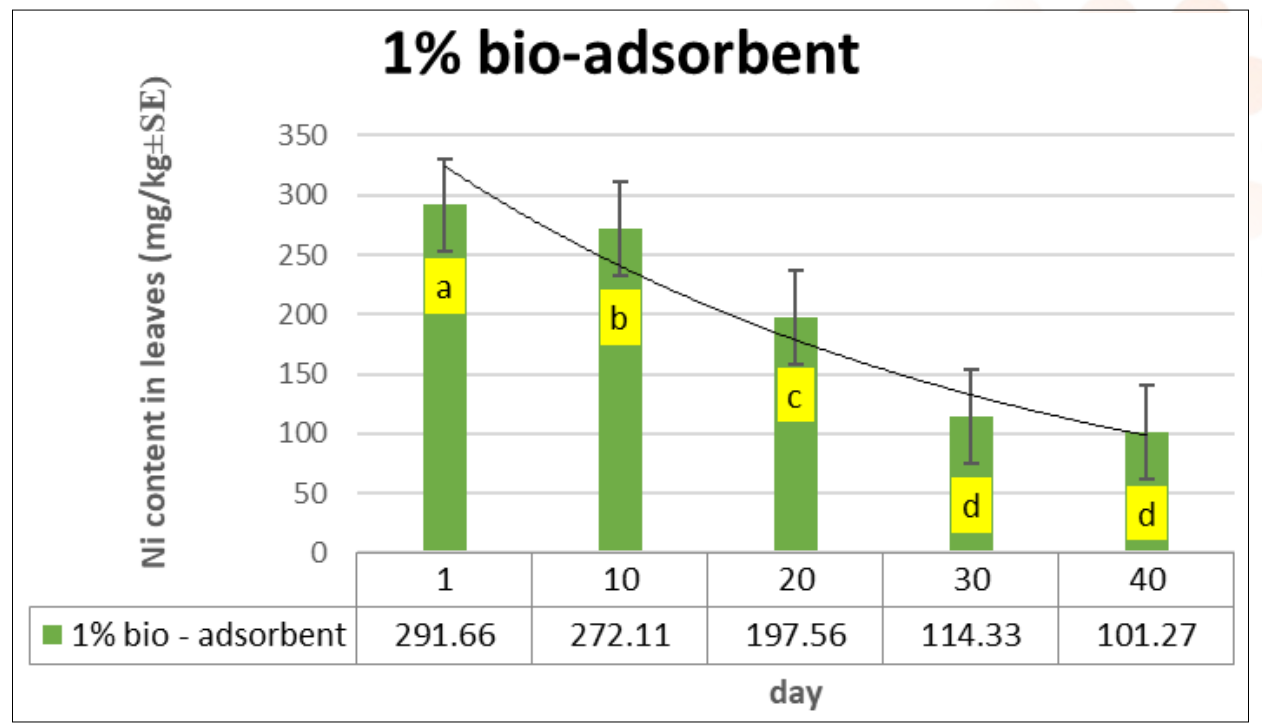

Figure 3: Effect of contact time on the removal of Nickel from leaves of vegetable (initial Ni concentration=336.76 mg $/ \mathrm{kg}$, bioadsorbent dose $=1 \%$ Coffee waste, temperature $=25 \pm 2{ }^{\circ} \mathrm{C}$.

Figure 3 revealed the results in presence of $1 \%(\mathrm{w} / \mathrm{w})$ bio-adsorbent. Although by passing 30 days the main part of Nickel contents from vegetable leaves were significantly decreased $(p<0.01)$, after 40 days the $70 \%$ removal of initial concentration of Nickel were observed, that means so significant $(p<0.001)$.

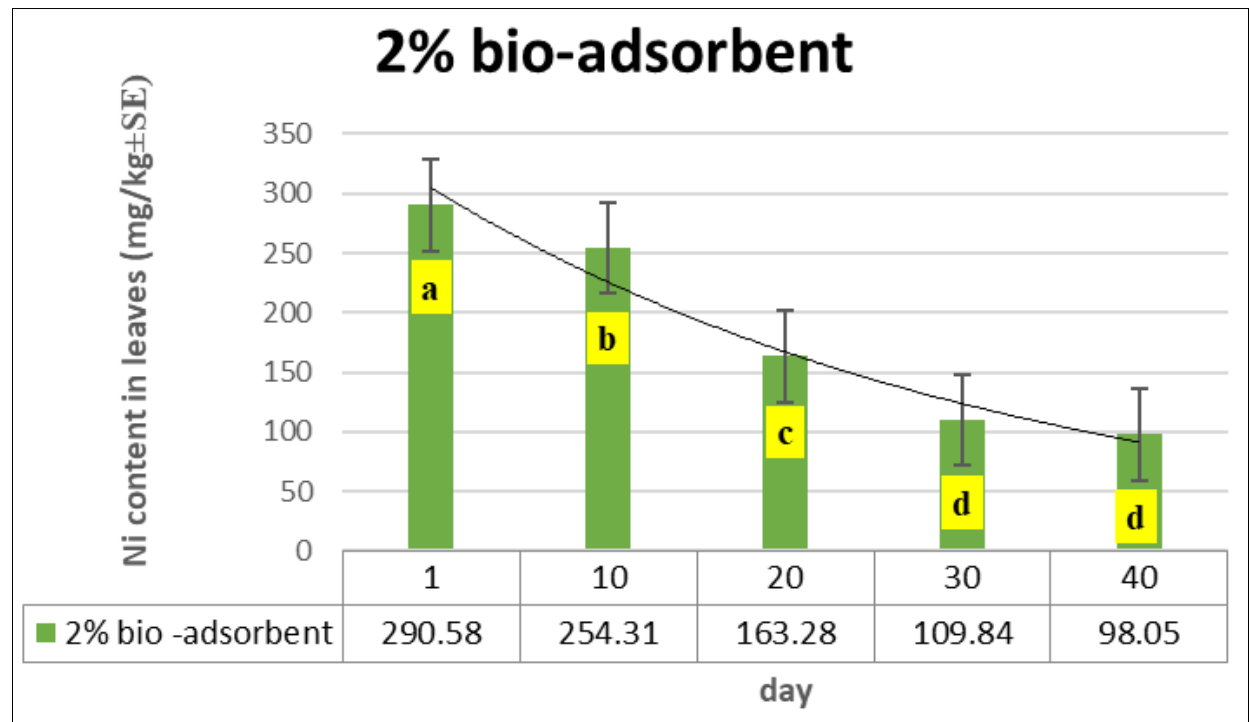

Figure 4: Effect of contact time on the removal of Nickel from leaves of vegetable (initial Ni concentration=336.76 mg $/ \mathrm{kg}$, bioadsorbent dose $=2 \%$ Coffee waste, temperature $=25 \pm 2{ }^{\circ} \mathrm{C}$.

The results from proceeding by $2 \%$ bio-adsorbent showed progressive leading. Moreover, time factor of putting Coffee bean waste (CBW) adsorbent in contaminated soil which irrigated by Pharmaceutical effluent by Nickel in the study declared significant effect $(p<0.01)$ and positive correlation with contents of $\mathrm{Ni}(\mathrm{r}=+89$ to $\mathrm{r}=+94)$, in the Aerial parts of Coriander: leaves in 10 days contact respectively. The amounts of Nickel adsorbed increased significantly with increase contact time $(p<0.001)$ in presence of $2 \%$ bio-mass (CBW). 


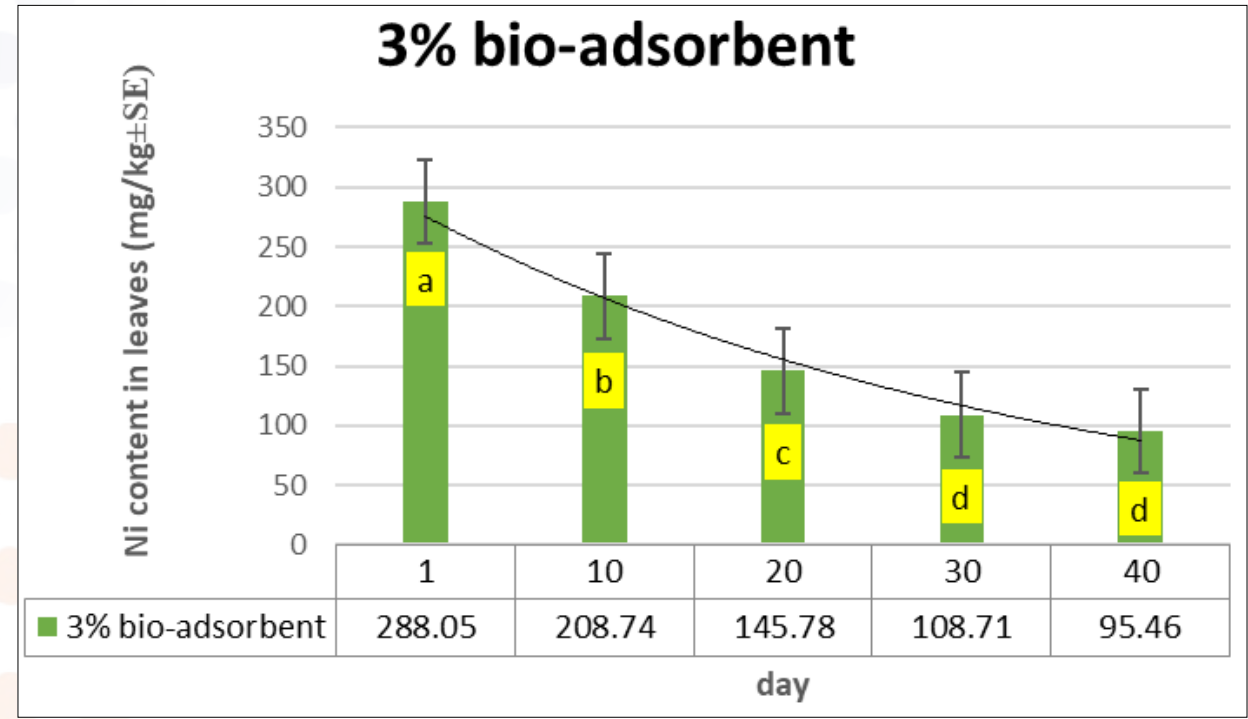

Figure 5: Effect of contact time on the removal of Nickel from leaves of vegetable (initial Ni concentration=336.76 mg $/ \mathrm{kg}$, bioadsorbent dose $=3 \%$ Coffee waste, temperature $=25 \pm 2{ }^{\circ} \mathrm{C}$.

In the figure 5; the potential of taking up Nickel was increased significantly between 10 days to 20 days in statistic state ( $p$ $<0.001)$ and $\mathrm{Ni}$ contents in edible leaves vegetable decreased from $336.76 \pm 0.02 \mathrm{mg} / \mathrm{Kg}$ in the beginning of survey to 208.74 $\pm 0.04 \mathrm{mg} / \mathrm{kg}$ which prove that biomass of adsorbent can reduce $62 \% \%$ of heavy metal even in a very short time. Likewise, time factor of putting adsorbent in contaminated soil by Pharmaceutical effluent and wastewater by Nickel in the study showed significant effect $(p<0.02)$ and positive correlation with contents of $\mathrm{Ni}(\mathrm{r}=+85$ to $\mathrm{r}=+94)$, in the edible vegetable and the content of bio-mass (CBW) in 10, 20 and 30 days of contact respectively. The amounts of Ni adsorbed increased significantly with increase contact time $(p<0.001)$ till 30 days of study and after that no significant removal was observed $(p>0.05)$.

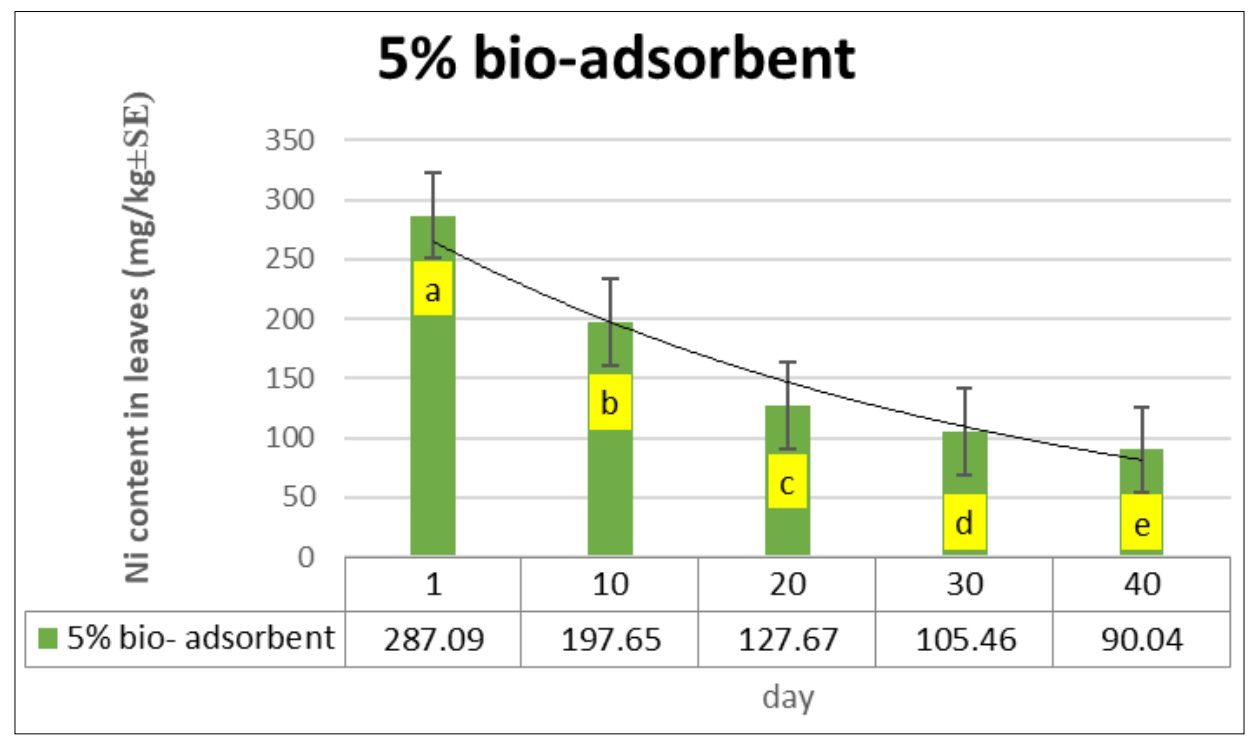

Figure 6: Effect of contact time on the removal of Nickel from leaves of vegetable (initial Ni concentration=336.76 mg $/ \mathrm{kg}$, bioadsorbent dose $=5 \%$ Coffee waste, temperature $=25 \pm 2{ }^{\circ} \mathrm{C}$. 


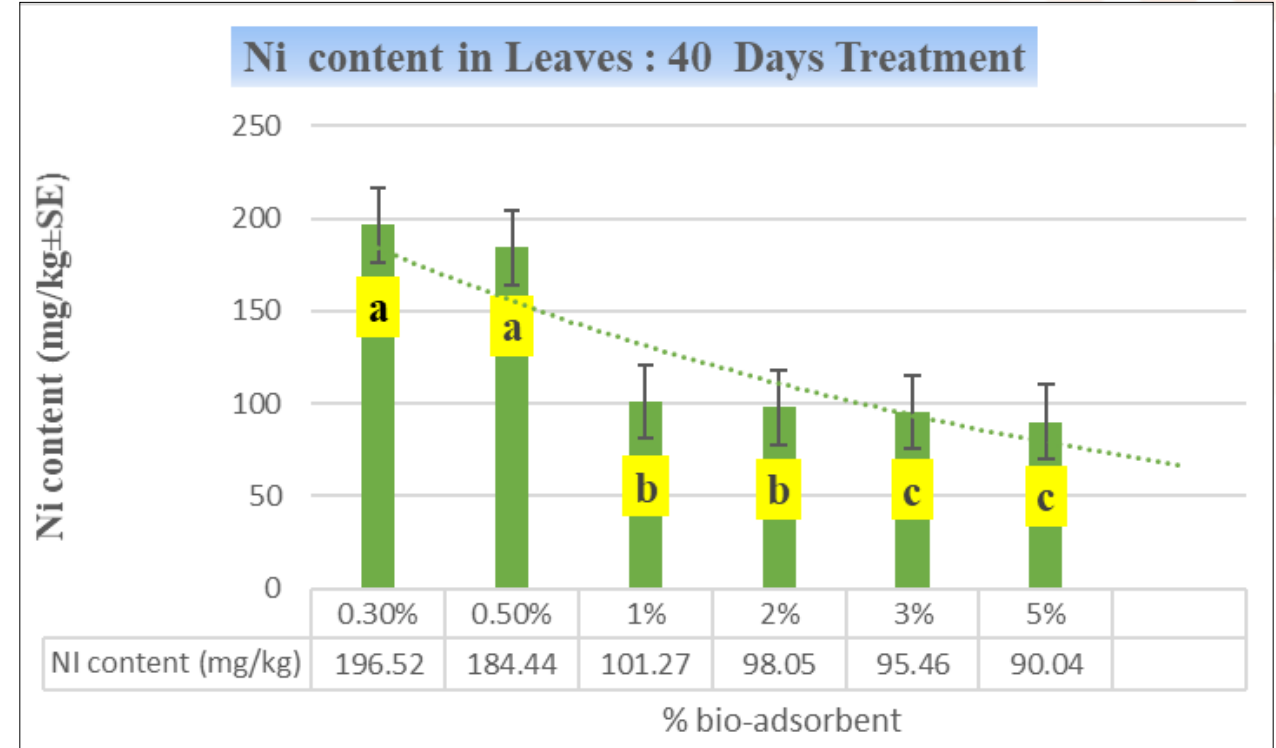

Figure 7: Effect of contact time on the removal of Nickel from leaves of vegetable (initial Ni concentration $=336.76 \mathrm{mg} / \mathrm{kg}$, bioadsorbent dose $=0.3 \%, 0.5 \%, 1 \%, 2 \%, 3 \%$ and $5 \% \mathrm{~W} / \mathrm{W}$ Coffee waste in contaminated soil.

In figure 7, the dose of adsorbent (CBW) were compared. The results revealed that there is no significance difference of increasing bio-mass percentage from $3 \%$ and $5 \%$ and also $1 \%$ by $2 \%, 0.3 \%$ and $0.5 \%$. As the growing process in $5 \%$ of bio-adsorbent did not lead to optimum conditions therefore the content of bio-mass of $3 \%$ is recommended for detoxification of Nickel content in high range in contaminated soils.

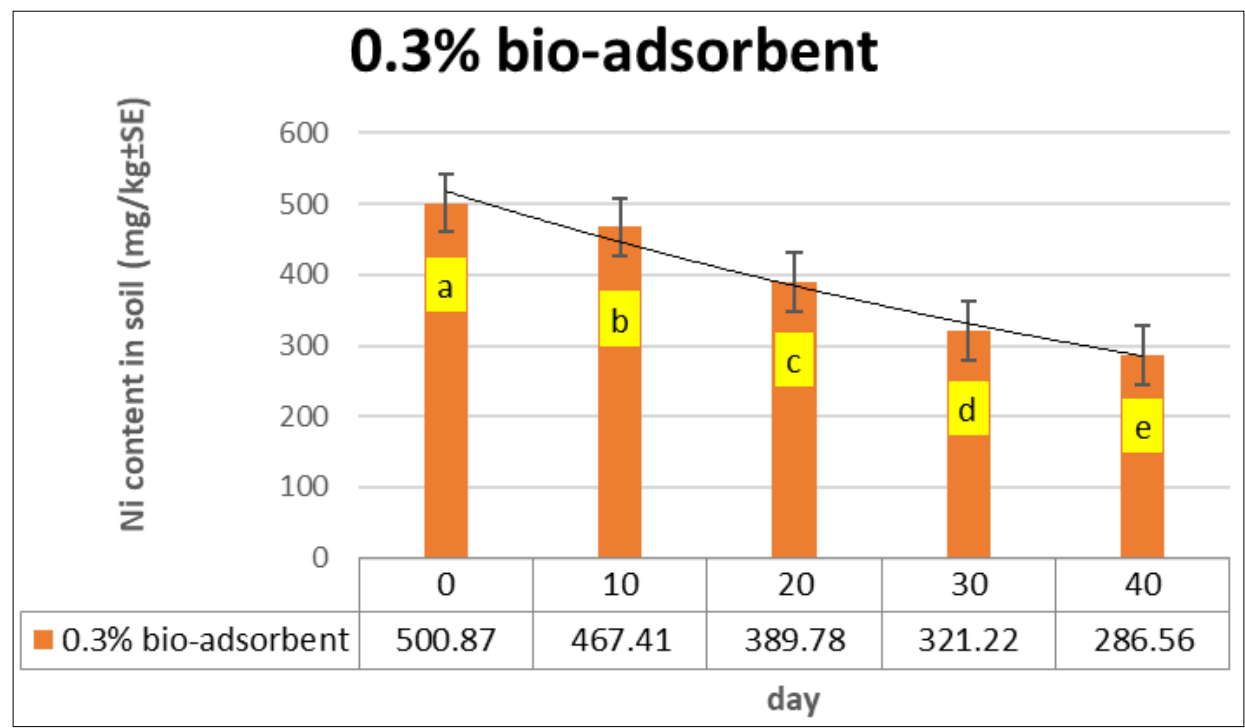

Figure 8: Effect of contact time on the removal of Nickel from soil (initial Ni concentration $=603.91 \mathrm{mg} / \mathrm{kg}$, bio-adsorbent dose $=0.3 \%$ Coffee waste, temperature $=25 \pm 2{ }^{\circ} \mathrm{C}$. 


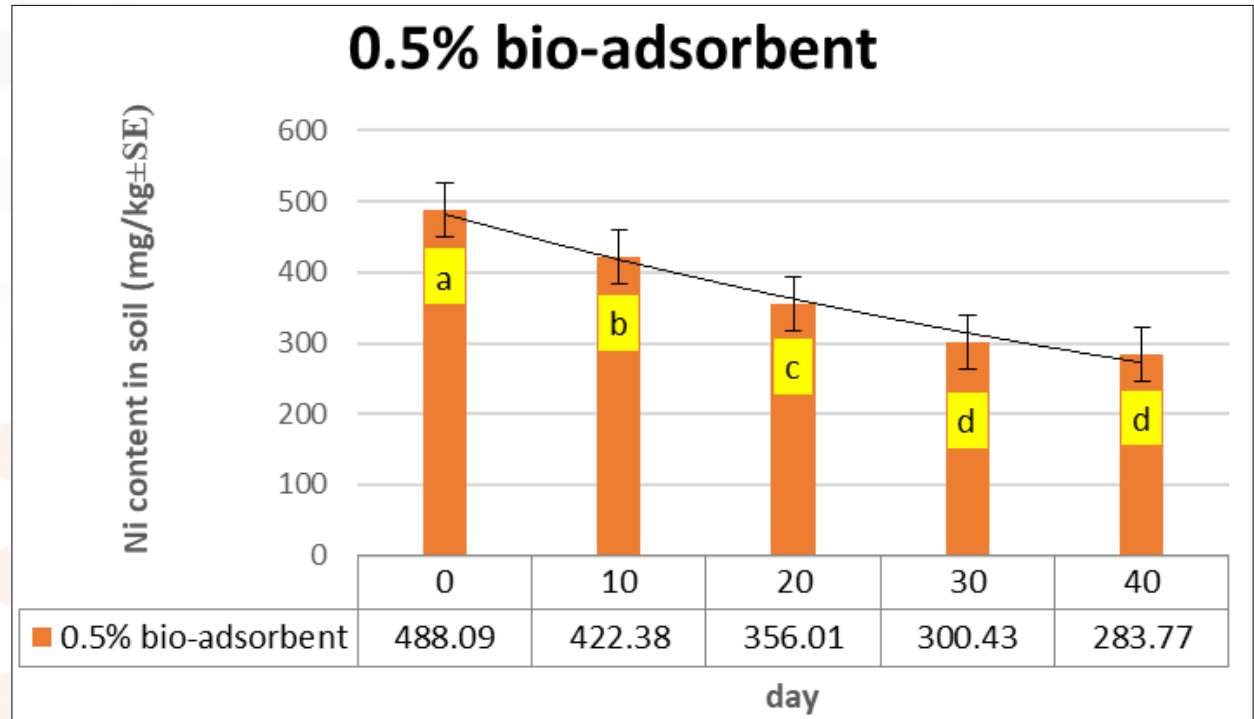

Figure 9: Effect of contact time on the removal of Nickel from soil (initial Ni concentration= $603.91 \mathrm{mg} / \mathrm{kg}$, bio-adsorbent dose $=0.5 \%$ Coffee waste, temperature $=25 \pm 2{ }^{\circ} \mathrm{C}$.

In figures 8 and 9 the Nickel contents in companionship of $0.3 \%$ and $0.5 \%$ of CBW in the soil of studied vases for growing up Coriandrum sativum (coriander) vegetable leaves could be compared. The decreasing level of Ni contents trend even in contaminated soils in company of Coffee bean waste as bio-adsorbent showed that probably complicated molecules in Coffee waste by chelating agents are rapidly excreted over a few hours or days can lead to build the firm complex and the chelating agents-ligands which are able to form two or more coordinate covalent bonds with a Nickel metal ion.

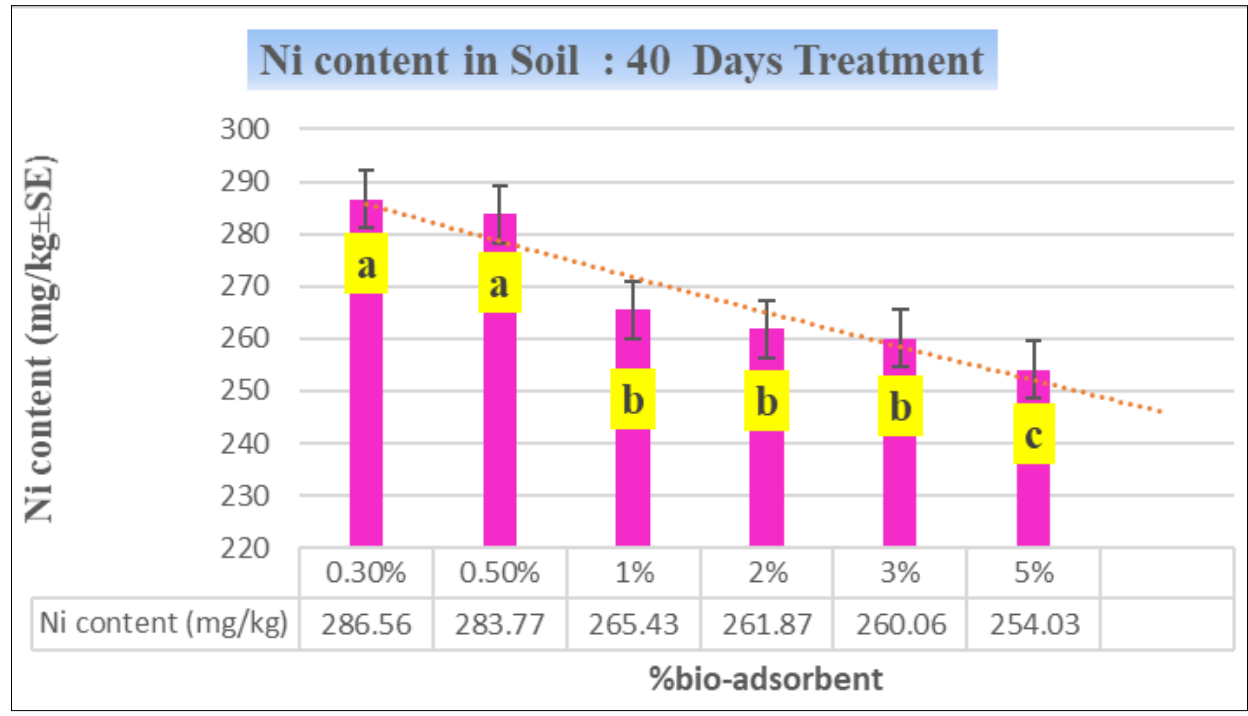

Figure 10: Effect of contact time on the removal of Nickel from soil (initial Ni concentration= $603.91 \mathrm{mg} / \mathrm{kg}$, bio-adsorbent dose $=0.3 \%, 0.5 \%, 1 \%, 2 \%, 3 \%$ and $5 \% \mathrm{~W} / \mathrm{W}$ Coffee waste in contaminated soil.

In figure 10, Ni contents remaining in contaminated soil in company of bio-adsorbent were compared. Obviously by higher concentration of bio-mass the chelating and bonding process has been boosted.

\section{Discussion}

In the other studied in 2017 by Sobhani and Ziarati on Tangerine Peel as a one of the most common fruit waste materials for adsorbing the heavy metals from contaminated soil in order to bio-adsorbing Nickel, Cadmium and Lead from soil as well as vegetable Coriander which is cultivated and finally would be eaten by people associate with their geological behavior (BGR) when Sobhani and Ziarati and [48], Ziarati 2020 showed relevant results. The Packed Potting Soil purchased from recognized centers from Tehran market and 40 same vases in the same situation such as light, water, soil , temperature and other conditions were prepared. The seeds of Coriandrum sativum (coriander) were being planted directly on the ground after a cold in vases. Meanwhile in 35 vases the Tangerine peel (TP) by $1 \%, 3 \%, 5 \%$ dry weight percentage were mixed by soil, due to observing the effect of TP as adsorbent and in specified 
times of $0,10,20,30,40$ days in the leaves of edible vegetable in treated and untreated soils as an edible vegetable has been grown in these soil samples was studied. Results revealed that Tangerine peel has more potential to adsorb Cadmium and lead first days of study $(p<0.001)$ and adsorption capacity varied by considering the effects of various parameters like contact time, initial concentrations, $\mathrm{pH}$, and absorbent dose. TP can accumulate high level of Cadmium in a short time and the uptake rate by vegetable edible plant is significantly affected by their concentrations in the contaminated soil $(p<0.05)$, but adsorbing Nickel in a few percentages has been done. A contact time of 30 days by $5 \%$ Coriander was found to be optimum and after 40 days cadmium contents were not detected. Decreasing lead content after 20 days in treated soil samples by TP was significant. The results of that investigation proved that Agroindustrial residues, such as those generated in citric juice production plants, have also been used as a substrate for the removal heavy metals by high percentage.

Jafari et al., in 2016 conducted another study which focused on adsorption capacity of $\mathrm{Cr}$ (VI), $\mathrm{Cr}$ (III), $\mathrm{Co}$ and $\mathrm{Cd}, \mathrm{Ni}$ and $\mathrm{Pb}$ by E. amoenum in a batch system by considering the effects of various parameters like contact time, initial concentrations, $\mathrm{pH}$, temperature, absorbent dose [ 47]. The results of this study revealed that $\mathrm{E}$. amoenum fruit can accumulate high level of Cobalt, Chrome (VI) and (III) in a short time and their uptake rate by vegetable and edible plant is significantly affected by their concentrations in the contaminated soil $(p<0.05)$. A contact time of 15 days by E. amoenum was found to be optimum and $90.6 \% \mathrm{Cr}$ (VI), 82.3\% Cr(III), $78.9 \%$ Co, 70.3\% $\mathrm{Pb}$ and $48.6 \% \mathrm{Ni}$ was taken by adsorbent from contaminated soil while a few amounts of these heavy metals being uptake by edible vegetable - basil.

Shokri et al., in 2016 investigated the potential ability of A. Vera for cleaning up contaminated educational sites soil and the probable capability of this plant to phytoextract different metals (Chrome (III) and (VI), Nickel, Copper, Lead and Cadmium) [2]. The initial concentration of heavy metals/ metalloid in the plants and effluents were analyzed before introduction into the studied soil samples. After 10 days of treatment up to 60 days in every ten days, final concentration of heavy metals/metalloid in effluent samples and plants were analyzed using Atomic Absorption Spectroscopy. Results showed that A. Vera transition factors for all heavy metals in treated soil were higher than one and A. Vera can up-take lead and Cadmium after 20 days $(p<0.01)$ more than other studied metals. A highly significant, although low, positive correlation $(\mathrm{r}=0.52, \mathrm{p}=0.01, \mathrm{n}=200)$ was found between Lead and Cadmium and chrome (III) of the greenhouse-grown A. Vera, compared to a non-significant and much lower correlation between the three other heavy metals: Nickel, $\mathrm{Cr}(\mathrm{VI})$ and Copper . The phytoremediation of lead and Cadmium trend by this plant indicates that A.vera cultivated in the soil can be consider as a suitable hyper-accumulator by its relatively large ratio of biomass concentration of the contaminant to soil concentration. The survey proved that the A. Vera was effective and inexpensive adsorbent for the removal of $\mathrm{Pb}, \mathrm{Cd}, \mathrm{Ni}, \mathrm{Cu}$, $\mathrm{Cr}$ (III) and (VI) from contaminated soil by heavy metals.
In the current study the rate of Nickel detoxification in Coriandrum sativum (coriander) vegetable leaves increased y raising the bio-adsorbent content from $3 \%$ up to $5 \%$ of (CBW) bio-mass $(71.6 \%$ to $73.3 \%$ ), but the rate of growing vegetable and the number of leaves decreased $(p<0.05)$ which showed excess bio-mass for growing up vegetable is not suitable. In Figure 6, the removal trend of $\mathrm{Ni}$ is observed and the time factor in every ten days of study up to 40 days. The data showed that accomplishing of Nickel content in untreated samples 336.76 $\mathrm{mg} / \mathrm{kg}$ after 20 days decreased to $127.67 \mathrm{mg} / \mathrm{kg}$ which has significant difference by 30 days study $(p<0.05)$ in the same concentration of biomass. This content of adsorbent can reduce Nickel from $197.65 \mathrm{mg} / \mathrm{kg}$ in the $20^{\text {th }}$ day of study to $90.04 \mathrm{mg} /$ $\mathrm{kg}$ in $40^{\text {th }}$ days.

The results of current study revealed that Nickel adsorption from contaminated soil ranged from $52.5 \%$ in the samples by $0.3 \% \mathrm{CBW}$ up to $57.9 \%$ by $5 \% \mathrm{CBW}$ after 40 days treatment by bio-mass and there was no significant further increase in $\%$ sorption of them after this time of study $(p \geq 0.05)$. There was no significance difference in detoxification of contaminated soil between $0.3 \%$ and $0.5 \%$ of bio-adsorbent while by extension of higher contents of CBW to $1 \%$ the more chelating process significantly were achieved but by further amounts and contents of bio-mass up to $5 \%$ there were no significant developing processes appeared. The best results arrived by $5 \%$ $\mathrm{CBW}$ while in this concentration the growing conditions of edible vegetable and plants was not suited and the soil became so rigid and lacks of necessary pores lead to logically it does not contribute to a soil's suggested productivity.

\section{Conclusion}

The present study focused on adsorption capacity of Ni by Coffee been waste was investigated in a batch system by considering the effects of various parameters like contact time, initial concentrations, $\mathrm{pH}$, temperature, absorbent dose. The results of current study revealed that can accumulate high level of $\mathrm{Ni}$ in a short time and their uptake rate by vegetable and edible plant is significantly affected by their concentrations in the contaminated soil $(p<0.003)$. In conclusion, Waste of Coffee could be a good adsorbent to remove heavy metals from soil amendments and improve the safety of vegetable and soil in the same time.

\section{Acknowledgment}

Nutrition \& Food Sciences Research Center, Islamic Azad University Medical Sciences Tehran, Tehran-Iran (IAUMST) is gratefully acknowledged.

\section{Conflicts of Interest}

None of the authors have any conflicts of interest associated with this study. 
References

1. Arabian S, Ziarati P, Sawicka B (2020) Waste Herbal and Black Tea as a Novel Adsorbent for Detoxification of Pharmaceutical Effluent, J Med Discov 5(3): DOI: 10.24262/jmd.5.3.20040.

2. Shokri F, Ziarati P, Mousavi Z (2016) Removal of Selected Heavy Metals from Pharmaceutical Effluent by Aloe Vera L. Biomedical Pharmacol J 9(2): 705-713.

3. Karimi G., Ziarati P (2015) Heavy Metal Contamination of Popular Nail Polishes in Iran, Iranian Journal of Toxicology 9(29): 1290-1295; http://ijt.arakmu.ac.ir/ article-1-410-en.pdf;

4. ZIARATI P., HOCHWIMMER B., LAMBERT BROWN D., MORADI M., CRUZ-RODRIGUEZ L. (2020) Breast Cancer disease and Heavy Metal: Cadmium as Key in Medical Geology. Journal of Gynecology and Women's Health Care 2(2): 1-13.

5. Ziarati P., Mirmohammad Makki F.S., Vambol S., Vambol V (2019) Determination of Toxic Metals Content in Iranian and Italian Flavoured Olive Oil. Acta Technologica Agriculturae Journal 22(2): 64-69. DOI: 10.2478/ata2019-0012.

6. Grandjean P. Human exposure to nickel. IARC Sci Publ 53:469-485.

7. Ziarati P., Shirkhan F., Mostafidi M., Tamaskani-Zahedi M (2018) An Overview of the Heavy Metal Contamination in Milk and Dairy Products. Acta Scientific Pharmaceutical Sciences 2.7: 08-21.

8. Ziarati P, Mostafidi M, shirkhan F, Tamaskoni Zahedi M (2018) ANALYSIS OF REMOVAL METHODS OF TOXIC HEAVY METALS USING BIO-ABSORBS. TECHNOGENIC AND ECOLOGICAL SAFETY 4(2): 62-76. DOI: 10.5281 /zenodo.1402587.

9. Razafsha A, Ziarati P (2016) Removal of Heavy Metals from Oryza sativa rice by sour lemon peel as bio-sorbent. Biomedical Pharmacol J 9(2): 739-749.

10. Ziarati, P, MirMohammad-Makki F, Moslehishad M (2016) Novel Adsorption Method for Contaminated Water by Wild Endemic Almond: Amygdalus scoparia. Biosciences Biotechnology Research Asia 13(1): 147-153.

11. Motaghi M, Ziarati P (2016) Adsorptive Removal of Cadmium and Lead from Oryza sativa Rice by Banana Peel as Biosorbent. Biomed Pharmacology J 9(2): 543553.

12. Ziarati $\mathrm{P}$, El-Esawi $\mathrm{M}$, sawicka $\mathrm{B}$, Umachandran $\mathrm{K}$, Mahmoud AED, Hochwimmer B, Vambol S, Vambol V (2019) Investigation of Prospects for Phytoremediation Treatment of Soils Contaminated with Heavy Metals. J Med Discov 4(2): 1-16. jmd19011; DOI:10.24262/ jmd.4.2.19011.

13. Hochwimmer B, Ziarati P, Selinus O, Elwej A, CruzRodriguez LD, Lambert Brown D, Zayas Tamayo AM, Moradi M, Cruz-Rodriguez L (2020) A Predictive Geological Tool of Type 3 Diabetes (Alzheimer's disease): The Polygonal Vortex Mineralisation Model a Medical Geology Perspective. Journal of Diabetes and Endocrinology Research 2(2): 1-15.
14. Mousavi Z, Ziarati P, Shariatdoost A (2013) Determination and safety assessment of lead and cadmium in eye shadows purchased in local market in Tehran. J Environ Anal Toxicol 3 (193), 2161-0525.1000193.

15. Ziarati P, Mohsenin Moshiri I, Sadeghi P (2017) Bioadsorption of Heavy Metals from Aqueous Solutions by Natural and Modified non-living Roots of Wild Scorzonera incisa DC. J Sci Discov 1(1). jsd17010; DOI:10.24262/ jsd.1.1.17010.

16. George Z. Kyzas (2012) Commercial Coffee Wastes as Materials for Adsorption of Heavy Metals from Aqueous Solutions. Materials 5: 1826-1840; doi:10.3390/ ma5101826.

17. Ziarati P, Moradi D, Vambol V (2020) Bioadsorption of heavy metals from the pharmaceutical effluents, contaminated soils and water by food and agricultural waste: a short review. Labour Protection Problems in Ukraine 36(2): 3-7. DOI: 10.36804/nndipbop.36-2.2020.3-7.

18. Mehrarad F, Ziarati P, Mousavi Z (2016) Removing Heavy Metals from Pharmaceutical Effluent by Pelargonium Grandiflorum. Biomedical \& Pharmacology Journal 9(2): 151-161.

19. Jallilian Z, Ziarati P (2016) High potential of Ferulago Angulate ( Schecht) Boiss in Adsorption of Heavy Metals. Biomed Pharmacol J 9(1): 201-208.

20. Sobhani L, Ziarati P (2017) Study on potential bioadsorption of Tangerine peel in removal of heavy metals: $\mathrm{Pb}, \mathrm{Cd}$ and $\mathrm{Ni}$ of vegetable coriander. J Sci Discov 1(2). jsd17020; DOI:10.24262/jsd.1.2.17020.

21. Pujol D, C. Liu, H. Pereira, et al. (2013) The chemical composition of exhausted coffee waste Industrial Crops and products 50: 423-429. DOI: $10.1016 / \mathrm{j}$. indcrop.2013.07.056.

22. Tim X Lee .COVID-19 Heavy Metal Hypothesis , https:// www.qeios.com/read/OF0L6S.3

23. Kyzas, G.Z.; Kostoglou, M.; Lazaridis, N.K (2009) Copper and chromium (VI) removal by chitosan derivativesEquilibrium and kinetic studies. Chem. Eng. J 152: 440 448.

24. Boonamnuayvitaya, V.; Chaiya, C.; Tanthapanichakoon, W.; Jarudilokkul, S (2004) Removal of heavy metals by adsorbent prepared from pyrolyzed coffee residues and clay. Sep. Purif. Technol 35: 11-22.

25. Laribi B, Kouki K, M'Hamdi M, Bettaieb T (2015) Coriander (Coriandrum sativum L.) and its bioactive constituents. Fitoterapia 103: 9-26.

26. Priyadarshi S, Khanum H, Ravi R, Borse BB, Naidu MM (2016) Flavour characterization and free radical scavenging activity of coriander (Coriandrum sativum L.) foliage. Journal of Food Science and Technology 53(3): 1670-1678.

27. Mandal S, Mandal M (2015) Coriander (Coriandrum sativum L.) essential oil: Chemistry and biological activity. Asian Pacific Journal of Tropical Biomedicine 5(6): 421-42.

28. Nadeem M, Anjum FM, Khan MI, Tehseen S, El-Ghorab A, Sultan JI (2013) Nutritional and medicinal aspects of coriander (Coriandrum sativum L.). A review. British 
Food Journal 115(5): 743-755.

29. Kasmaei HD, Ghorbanifar Z, Zayeri F, Minaei B, Kamali SH, Rezaeizadeh H, Amin G, Ghobadi A, Mirzaei Z (2016) Effects of Coriandrum sativum syrup on migraine: A randomized, triple-blind, placebo-controlled trial. Iranian Red Crescent Medical Journal 18(1): e20759.

30. Pourzare A, Ziarati P, Mousavi Z, Faraji AR (2017) Removing Cadmium and Nickel Contents in Basil Cultivated in Pharmaceutical Effluent by chamomile (Matricaria chamomilla L.) Tea Residue. J Sci Discov 1(1). jsd17006; DOI:10.24262/jsd.1.1.17006.

31. Tavakoli-Hosseinabady B, Ziarati P, Ballali E, Umachandran K (2018) Detoxification of Heavy Metals from Leafy Edible Vegetables by Agricultural Waste: Apricot Pit Shell. J Environ Anal Toxicol 8(1): 548. doi: 10.4172/2161-0525.1000548.

32. Ziarati P, Davoudi, MHS, Kozub SM. et al. (2020) Sposib ochyshchennya vody [Method of water purification]. Ukrainian Patent NO. u 202002228 Kyiv: State Patent Office of Ukraine 2020.

33. Ziarati P, Ghasemynezhad-Shanderman S.S (2014) MINERAL CONTENTS IN PLEUROTUS (OYSTER MUSHROOM): ASSOCIATION OF COOKING METHOD. International Journal of Plant, Animal and Environmental Sciences 4(2): 496-501.

34. Ahmadi A, Ziarati P (2015) Chemical composition Profile of Canned and Frozen Sweet Corn ( Zea mays L.) in Iran. Oriental Journal of Chemistry 31(2): 1065-1070.

35. Ziarati P, Farasati Far B, Mashayekhi E, Sawicka B. Removing arsenic by food-processing waste (Zizyphus jujuba seeds) and study on its adsorptive properties. Technogenic and ecological safety. 2019; 5(1): 62-70. DOI: 10.5281 /zenodo.2604648.

36. Ahmadi A, Ziarati P (2015) Chemical composition Profile of Canned and Frozen Sweet Corn ( Zea mays L.) in Iran. Oriental Journal of Chemistry 31(2): 1065-1070.

37. Ziarati P, Mostafidi M, Arabian S. et al. (2019) Patent № 138281 Ukraina, Sposib ochystky vody. Zayavka № u201904687; zayavl. 02.05.2019; opubl. 25.11.2019, Byul. № 22/2019.

38. Alimardan M, Ziarati P, Jafari Moghadam R (2016) Adsorption of Heavy Metal Ions from Contaminated Soil by B. Integerrima Barberry. Biomedical Pharmacol J 9(1): 169-175.

39. Yazdanparast S, Ziarati P, Asgarpanah J (2014) Heavy Metals and Mineral Content and Nutritive Value of Some Iranian Manna. BBRA 11(2): 1025-1029.

40. AOAC (2000) Method 962.09. Official Methods of Analysis of AOAC International, 17th ed. 14 ed., AOAC International, Gaithersburg: Maryland USA, ISBN: 09355846769780935584677.

41. Alidoost-Saharkhiz-Lahiji F, Ziarati P, Jafarpour A (2016) Potential of Rice Husk Biosorption in Reduction of Heavy Metals from Oryza sativa Rice, BIOSCIENCES BIOTECHNOLOGY RESEARCH ASIA 13(4): 22312237.

42. Gholizadeh E, Ziarati P (2016) Remediation of Contaminated Rice Farmlands Soil and Oryza sativa Rice
Product by Apple Pomace as AdsorbentRemediation of Contaminated Rice Farmlands Soil and Oryza sativa Rice Product by Apple Pomace as Adsorbent. BBRA 13(4): 2245-2253.

43. Gorgani S, Ziarati P (2020) Study on Potential Environmental Adsorption of Egg shells to Removal of Lead and Cadmium from Oriza Sativa Rice. Medical Science Journal of Islamic Azad University, Tehran Medical Branch 30(2): 155-166.

44. Ziarati P, Tosifi P(2014)COMPARING SOME PHYSICAL AND CHEMICAL PROPERTIES OF GREEN OLIVE (OLEA EUROPEA L.) IN IRAN ASSOCIATION WITH ECOLOGICAL CONDITIONS. International Journal of Plant, Animal and Environmental Sciences 4(2): 519-528.

45. Ziarati P (2012) Determination of Contaminants in Some Iranian Popular Herbal Medicines: Journal of Environmental \& Analytical Toxicology 2(1): 1.

46. Mousavi Z, Ziarati P, Esmaieli M, Qomi M (2014) Heavy metals (Lead and Cadmium) in some medicinal herbal products in Iranian market. Iranian Journal of Toxicology 8(24): 1004-1010.

47. Jafari A, Amin G, Ziarati P (2016) Potential of Echium ameonum Fisch \& Mey in Removing Heavy Metals from Pharmaceutical Effluent Bioscience \& Biotechnology Research Asia 13(3): 1585-1594.

48. Ziarati P., Kamyab-Moghadas B., Cruz-Rodriguez L," (2020) Breast cancer disease and Arsenic: "GEOLOGICAL BEHAVIOR (GBR) as Key "Gynecology and Women's Health Care Volume 2 Issue 3.

49. Zahirnejad M, Ziarati P, Asgarpanah J (2017) The Efficiency of Bio-adsorption of Heavy Metals from Pharmaceutical Effluent by Rumex crispus L. Seed. Journal of Pharmaceutical and Health Sciences 5(3): 231243.

50. Shahsavan-Davoudi AH, Ziarati P (2020) Green Method for Cadmium Removal from Pharmaceutical Effluent Laboratories by Grapefruit Peel. jmd20036; DOI:10.24262/jmd.5.3.20036.

Copyright: (C2020 . Luis CRUZ RODRIGUEZ . This is an open-access article distributed under the terms of the Creative Commons Attribution License, which permits unrestricted use, distribution, and reproduction in any medium, provided the original author and source are credited. 